\title{
PROJETO ESTRUTURAL DE UMA CERVEJARIA COM A UTILIZAÇÃO DO SOFTWARE
}

\section{EBERICK}

STRUCTURAL DESIGN OF A BEERHOUSE WITH THE USE OF THE EBERICK SOFTWARE

Hananias Alves dos Santos ${ }^{1}$

Gilsinei da silva²

\section{RESUMO}

O concreto armado é uma das principais técnicas utilizadas na atualidade, sendo assim, é de fundamental importância para o engenheiro saber como dimensionar e detalhar corretamente todos os elementos de uma estrutura. Portanto, este trabalho irá mostrar a maneira correta, de como dimensionar e detalhar com segurança uma estrutura em concreto armado, utilizando a ancoragem do software Eberick da empresa AltoQi. Para isto foi realizado uma ampla pesquisa bibliográfica, para ter um conhecimento avançado de qual a melhor maneira de fazer o dimensionamento da estrutura. Com o conhecimento adquirido foi feito lançamento da estrutura no software, detalhando também o passo a passo de todas as etapas até o processamento da estrutura, posteriormente foi feita a análise de todos os resultados fornecidos juntamente com o melhor arranjo de aço para atender as necessidades de cada elemento estrutural, onde também foi passado o resumo de todos os materiais utilizados.

Palavras-Chave: Concreto Armado. Engenheiro. Estrutura. Resultado. Resumo.

\section{ABSTRACT}

Reinforced concrete is one of the main techniques used today, so it is of fundamental importance for the engineer to know how to correctly dimension and detail all the elements of a structure. Therefore, this work will show the correct way, how to safely dimension and detail a reinforced concrete structure, using the anchorage of

\footnotetext{
${ }^{1}$ Acadêmico do Curso de Engenharia Civil da Universidade Alto Vale do Rio do Peixe (UNIARP). Email: hananiassantos@hotmail.com.

2 Professor Orientador. Graduado em Engenharia Civil, pela Universidade Federal de Santa Catarina, Especialista em Administração, Gestão Pública e Políticas sociais pela Faculdade Dom Bosco e docente do Curso de Engenharia Civil da Universidade Alto Vale do Rio do Peixe.
} 
AltoQi's Eberick software. For this, an extensive bibliographical research was done, to have an advanced knowledge of the best way to do the structure sizing. With the knowledge acquired, the structure was introduced in the software, detailing also the step-by-step of all the stages until the processing of the structure, afterwards the analysis of all the results provided along with the best steel arrangement to meet the needs of each structural element, where the summary of all materials used was also passed.

Keywords: Armed Concrete. Engineer. Structure. Result. Abstract.

\section{INTRODUÇÃO}

O objetivo geral deste trabalho de conclusão de curso, é fazer o dimensionamento da estrutura de uma cervejaria em concreto armado, utilizando o software de cálculo Eberick da empresa AltoQI.

Já os objetivos específicos são:

- Realização de pesquisa bibliográfica em livros e artigos, para assim aprofundar o conhecimento em concreto armado;

- Fazer o dimensionamento da estrutura utilizando o software Eberick;

- Analisar todos os resultados fornecidos pelo software;

- Fazer a apresentação do dimensionamento dos pilares, vigas e lajes do projeto.

Sendo assim, respondendo o problema de como dimensionar uma estrutura em concreto armado, fazendo o cálculo de todos os seus elementos estruturais utilizando o software Eberick com segurança?

\section{DESENVOLVIMENTO}

Para fazer o dimensionamento de uma estrutura primeiramente deve-se saber onde alocar todos os elementos que compõe uma estrutura. Sendo assim, tudo tem seu início no projeto arquitetônico, pois, é por meio dele que será feita a análise preliminar da estrutura, onde podemos começar a definir a melhor localização e posição dos elementos estruturais, tais como, vigas, pilares e lajes, para assim fazer o lançamento da estrutura.

Outro ponto que deve se ter conhecimento para a realização do 
dimensionamento de qualquer estrutura é o concreto, que segundo Leonhardt e Mönnig (2008, p. 3), "[...] é um aglomerado constituído de agregados e cimento como aglutinante, é portanto uma rocha artificial. A fabricação do concreto é feita pela mistura dos agregados (areia e cascalho) com cimento e água [...]".

Sabendo que o concreto tem uma ótima resitência a compressão e muito pouca resistência a tração, para que seja aumentada essa resistência é necessário que sejam colocadas barras de aço no interior do concreto, formando assim, o concrento armado.

Também é de suma importância saber todos os elementos que compõe uma estrutura, tais como:

- Lajes: São elementos na horizontal, pisos ou tetos de um edificil ou casa;

- Vigas: Tem como função absorver as cargas das lajes e das paredes;

- Pilares: Sua principal função é absorver as cargas geradas pelas vigas e transmitir para a fundação;

- Fundação: Tem a função se absorver a carga de toda a estrutura e trasmitir para o solo.

\section{METODOLOGIA}

A metodologia utilizada neste trabalho foi a pesquisa bibliográfica em livros, artigos e outros TCCs referentes ao assunto, além de vídeos e pesquisas na internet para se aprofundar melhor ao tema, buscando assim todo conhecimento necessário para o dimensionamento de uma cervejaria em concreto armado, seguindo todas as exigências na NBR 6118 (ABNT, 2014), para que haja uma correta segurança em toda a estrutura.

\section{ESPECIFICAÇÕES DO PROJETO}

O projeto a ser dimensionado e detalhado é de uma cervejaria industrial, projetada pelo arquiteto Marcelo Wandscheer, e será implantada na Estrada Cristóvão Machado de Campos 274 em Vargem Grande- Florianópolis/SC. Sendo assim, a cervejaria contará com 3 pavimentos, sendo eles: subsolo, térreo e superior, somando juntos, um total de 1079,69 m² de área construída. 


\section{APRESENTAÇÃO, ANÁLISE DOS DADOS E RESULTADOS}

Para iniciar o pré-dimensionamento dos elementos estruturais, serão verificados os dados fornecidos pelo arquiteto responsável pela elaboração projeto arquitetônico, sendo assim alguns elementos estruturais já contém uma seção prédefinida, como por exemplo, os pilares contendo seção $b=30 \mathrm{~cm}$ e $h=30 \mathrm{~cm}$, já as vigas possuíam seções $b w=20 \mathrm{~cm}$ e $h=40 \mathrm{~cm}$. Contudo, ao longo do dimensionamento, sabe-se que poderão haver algumas modificações, sendo preciso redimensionar alguns elementos estruturais

No dimensionamento das lajes, serão utilizadas lajes maciças em todos os pavimentos, já na fundação serão utilizadas sapatas.

As configurações do software foram adequadas para atender as necessidades deste projeto, sendo que todo processo será baseado nas normas da NBR 6118 (ABNT, 2014).

CONFIGURAÇÕES DO SOFTWARE DA ALTOQI - EBERICK

As configurações do software foram adequadas para atender as necessidades deste projeto, sendo que todo processo será baseado nas normas da NBR 6118 (ABNT, 2014).

\section{CONFIGURAÇÃO ANÁLISE}

As configurações de análises fornecidas pelo software nesta etapa foram mantidas, aumentado apenas a redução na torção dos pilares para $90 \%$.

\section{CONFIGURAÇÃO DETALHAMENTO}

Nesta etapa foi configurada somente as abas de Pilares, Vigas, Lajes e Sapatas, sendo as outras abas desconsideradas neste dimensionamento.

\section{CONFIGURAÇÃO DETALHAMENTO PILARES}

Nesta configuração foi apenas modificado a escala, para um melhor aproveitamento e alocação dos elementos nas pranchas. 


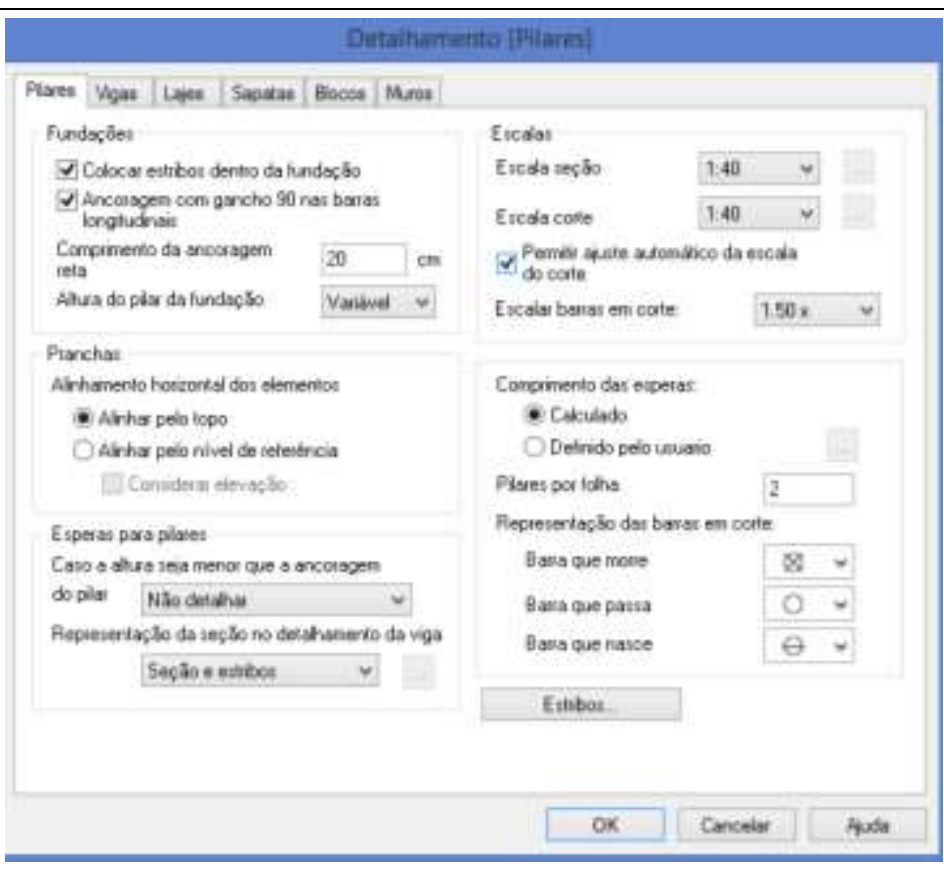

Figura 1 - Configuração detalhamento pilares

Fonte: O próprio autor

\section{CONFIGURAÇÃO DETALHAMENTO VIGAS}

Nesta configuração foram mantidos os dados fornecidos pelo software, portanto nao houve nenhuma modificação.

\section{CONFIGURAÇÃO DETALHAMENTO LAJES}

Nesta etapa foram mantidas todas as configurações fornecidas pelo software, ou seja, não houve nenhuma modificação.

\section{CONFIGURAÇÃO DETALHAMENTO LAJES ESCADAS}

A presente etapa não houve nenhuma modificação permanecendo os mesmos parâmetros fornecidos pelo software.

\section{CONFIGURAÇÃO DETALHAMENTO SAPATAS}

Nesta etapa, foram modificadas apenas as escalas, passando de 1:25 para 1:50, como pode ser visualizado na figura a seguir. 


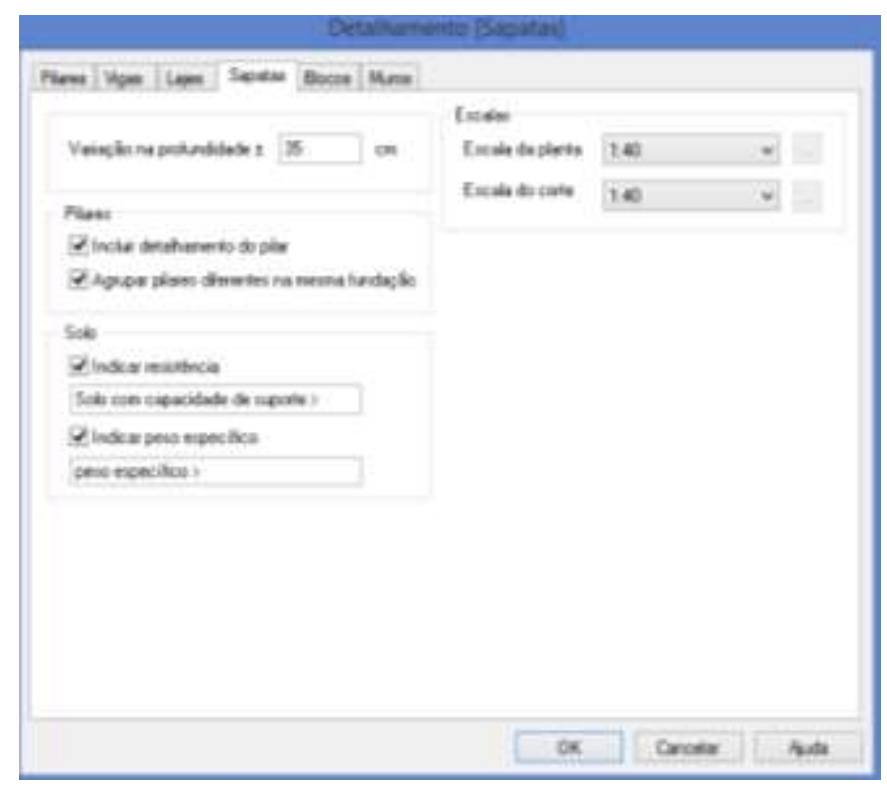

Figura 2 - Configuração detalhamento sapatas

Fonte: O próprio autor

\section{CONFIGURAÇÃO DIMENSIONAMENTO}

Para a configuração de dimensionamentos as únicas abas que serão modificadas são: Pilares, Vigas, Lajes e Sapatas, sendo que as demais abas não serão utilizadas para a realização deste trabalho.

\section{DIMENSIONAMENTO PILARES}

A única modificação existente nesta etapa foi a habilitação do item " permitir carga negativa".

\section{DIMENSIONAMENTO VIGAS}

Nesta configuração de dimensionamento, a única modificação ficou por conta do diâmetro mínimo da armadura de compressão que passou para $8 \mathrm{~mm}$.

\section{DIMENSIONAMENTO LAJES}

Nesta configuração não foram efetuadas modificações, permanecendo os 
valores fornecidos pelo software.

\section{DIMENSIONAMENTO SAPATAS}

Para esta etapa foi considerado o tipo de solo arenoso, permanecendo os demais valores fornecidos pelo software conforme a figura a seguir.

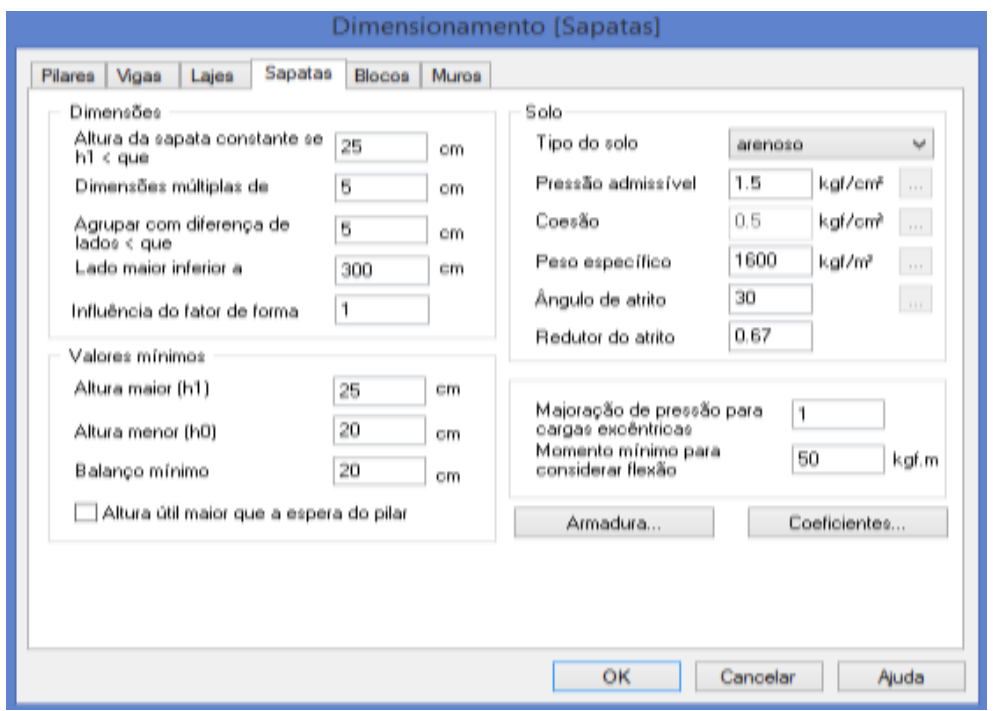

Figura 3 - Configuração dimensionamento sapatas

Fonte: O próprio autor

\section{CONFIGURAÇÃO DE MATERIAIS E DURABILIDADE}

Para a configuração de materiais e durabilidade, foram utilizados os seguintes parâmetros:

- Classe de agressividade: III (Forte);

- Dimensão do agregado: $19 \mathrm{~mm}$;

- Resistencia do concreto: $30 \mathrm{Mpa}$;

- Peso especifico do concreto: $2500 \mathrm{~kg} / \mathrm{m}^{3}$;

- Cobrimento de peças internas: $4 \mathrm{~cm}$;

- Cobrimento de peças externas: $4 \mathrm{~cm}$;

- Umidade relativa do ar: $70 \%$;

- Inicio do carregamento: 28 dias;

- Vida útil prevista: 50 anos; 
- Abertura máxima de fissuras em contato com o solo: 0,2 mm;

- Abertura máxima de fissuras em contato com a água: 0,1 mm;

- Abertura máxima de fissuras das demais peças: 0,3 $\mathrm{mm}$.

\section{CONFIGURAÇÃO SISTEMA}

$\mathrm{Na}$ configuração sistema que abrange todas as unidades de medida não foram feitas alterações, permanecendo assim as configurações fornecidas pelo software.

\section{LANÇAMENTO DA ESTRUTURA}

Todo o lançamento da estrutura será feito de acordo com a normatização e conforme dados dos elementos fornecidos no projeto, para que se tenha uma perfeita integração entre o projeto e seus elementos estruturais, os elementos estruturais a serem lançados neste projeto são: pilares, vigas, lajes e a fundação.

\section{LANÇAMENTO DOS PAVIMENTOS}

A primeira etapa do lançamento da estrutura foi a criação dos pavimentos, juntamente com a altura e os níveis de cada pavimento, entretanto para a primeira altura que seria a altura da fundação foi utilizado $150 \mathrm{~cm}$, como pode ser observado na imagem a seguir. 


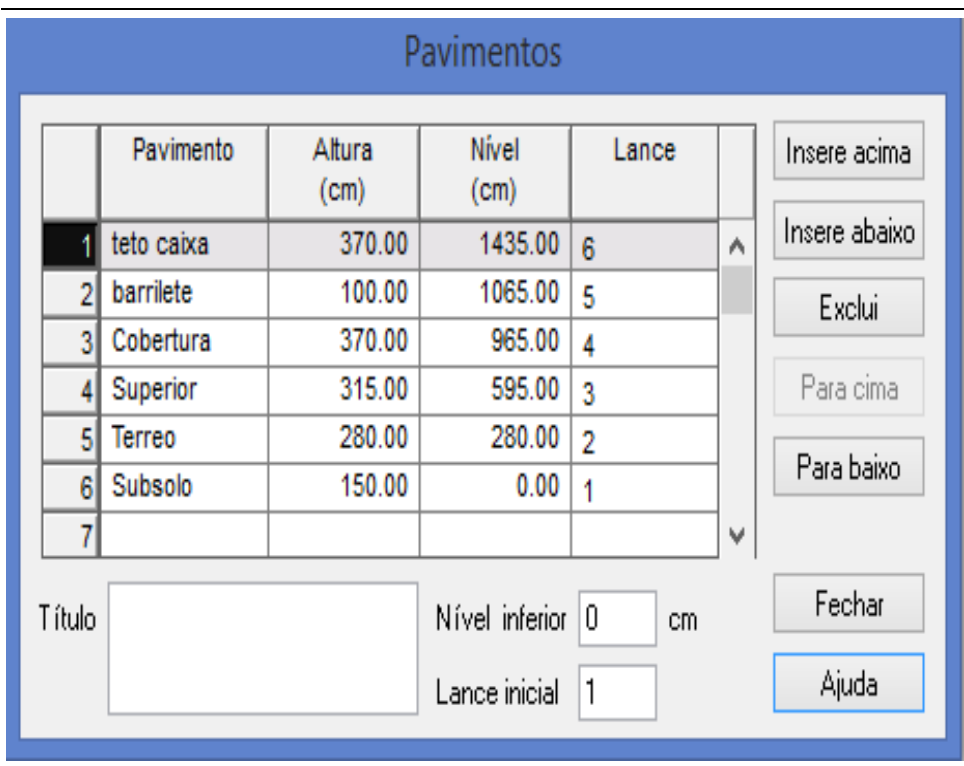

Figura 4 - Lançamento dos pavimentos

Fonte: O próprio autor

\section{LANÇAMENTO DOS PILARES}

O primeiro elemento estrutural a ser lançado no software são os pilares, que possui sua medida pré-definida de $b=30 \mathrm{~cm}$ e $\mathrm{h}=30 \mathrm{~cm}$, conforme definido pelo projetista, podendo sofrer algum tipo de alteração durante a execução do dimensionamento.

\section{LANÇAMENTO DAS VIGAS}

O segundo elemento a ser lançado serão as vigas, que também possuem uma medida pré-definida, sendo as da base, $b w=20 \mathrm{~cm}$ para pavimento subsolo e $b w=17 \mathrm{~cm}$ para os demais pavimentos, já sua altura varia entre $\mathrm{h}=50 \mathrm{~cm}$ para subsolo e $\mathrm{h}=40 \mathrm{~cm}$ para os demais pavimentos.

As vigas que possuírem apoios em outras vigas serão todas rotuladas, para assim evitar ao máximo o momento torsor na estrutura

\section{LANÇAMENTO DAS LAJES}

O terceiro elemento a ser lançado serão as lajes, que inicialmente todas irão ser maciças, já quanto a espessura poderá variar de $12 \mathrm{~cm}$ até $17 \mathrm{~cm}$, conforme a 
necessidade do projeto. A carga acidental irá ser $150 \mathrm{kgf} / \mathrm{m}^{2}$ e em áreas específicas podendo chegar até $1000 \mathrm{kgf} / \mathrm{m}^{2}$, entretanto, sua carga de revestimento será fixada em $100 \mathrm{kgf} / \mathrm{m}^{2}$.

\section{LANÇAMENTO DOS PAVIMENTOS}

\section{LANÇAMENTO DA FUNDAÇÃO}

O ultimo elemento a ser feito o lançamento será a fundação, que irá ser do tipo sapata e irá conter uma profundidade de $150 \mathrm{~cm}$.

\section{LANÇAMENTO DO PAVIMENTO SUBSOLO}

No pavimento subsolo foram lançados os pilares, onde todos foram convertidos para fundação, as vigas e as lajes.

\section{LANÇAMENTO DO PAVIMENTO TÉRREO}

Foi lançado no pavimento térreo os pilares, onde foram convertidos para fundação somente aqueles que não tinham continuidade com o pavimento fundação, também foram lançados as vigas, as lajes e a escada.

\section{LANÇAMENTO DO PAVIMENTO SUPERIOR}

No pavimento superior foram lançados os pilares, as vigas, as lajes e a escada.

\section{LANÇAMENTO DO PAVIMENTO COBERTURA}

Os elementos lançados neste pavimento foram apenas os pilares que possuem continuação com a caixa d'água, as vigas para suportar a cobertura e apenas duas lajes, sendo uma delas utilizada como cobertura.

\section{LANÇAMENTO DO PAVIMENTO BARRILETE}

Neste pavimento foi continuado os pilares, adicionado as vigas e as lajes que suportarão as caixas d'água. 
LANÇAMENTO DO PAVIMENTO TETO DA CAIXA D'ÁGUA

O lançamento neste pavimento foi apenas o das vigas e das duas lajes que servirão de cobertura.

PÓRTICO ESPACIAL

Por meio desde recurso oferecido pelo software, podemos visualizar o agrupamento de todos os elementos estruturais, fazendo com que nenhum detalhe passe despercebido.

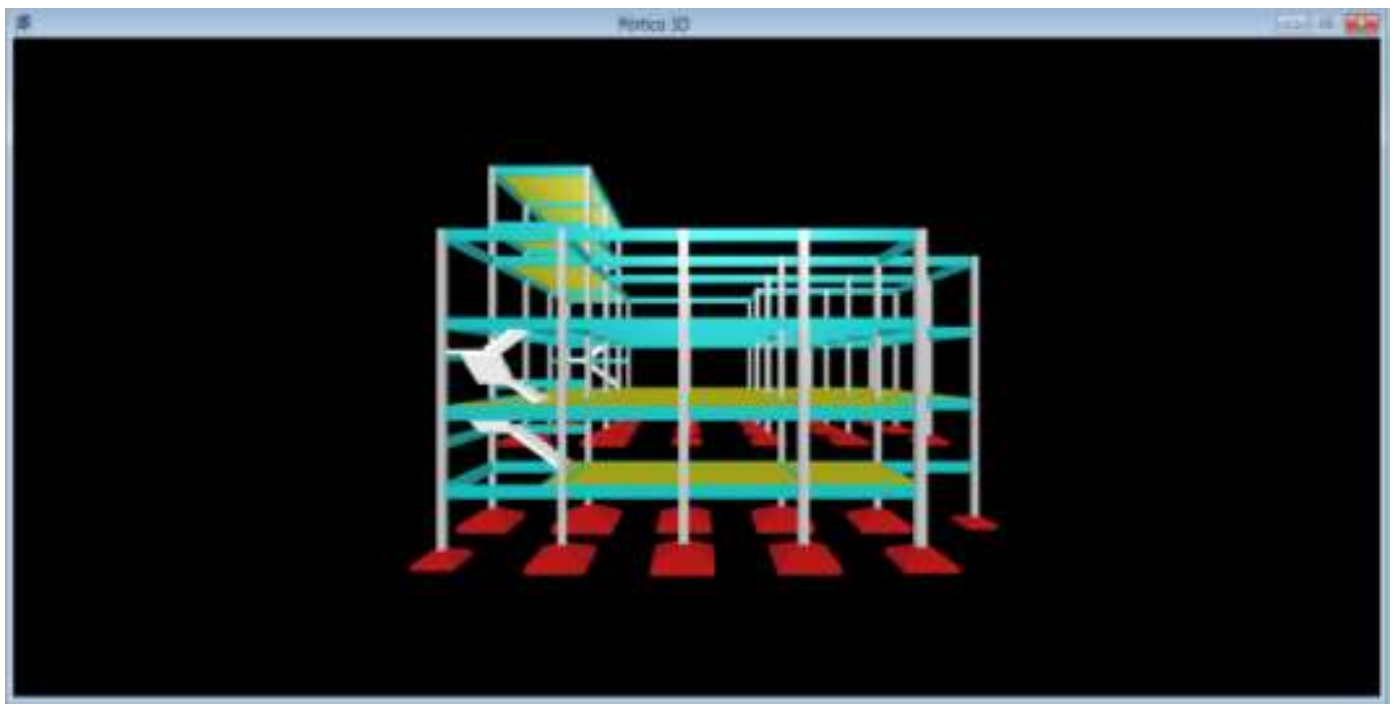

Figura 5 - Pórtico espacial vista frontal

Fonte: O próprio autor

PROCESSAMENTO DA ESTRUTURA

Após o lançamento da estrutura feito e verificado o pórtico 3D para ver se todos os elementos da estrutura estão agrupados corretamente, foi feito o processamento de toda a estrutura e conferido se tudo estava de acordo com o projeto.

Por meio dos resultados oferecidos, podemos verificar se todos os componentes foram dimensionados corretamente ou se houve algum erro durante o lançamento ou no processamento da estrutura, como pode ser visto na figura 8. 


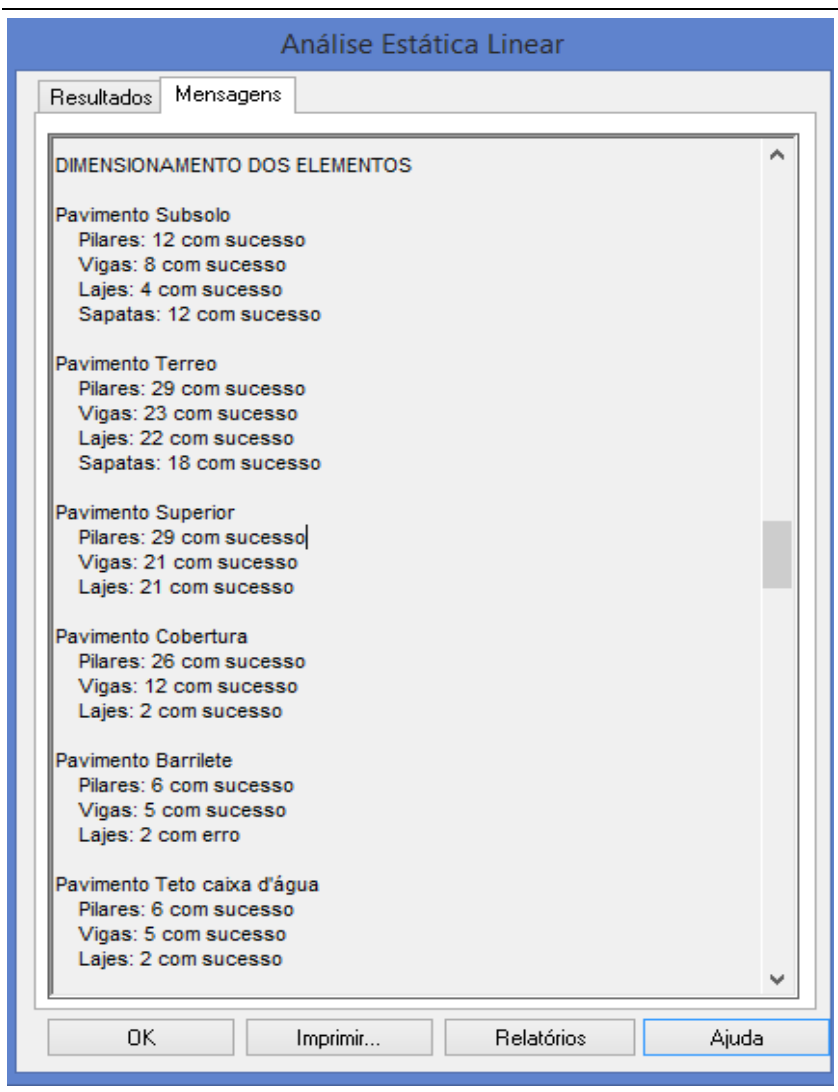

Figura 6 - Resultado do dimensionamento dos elementos na análise estática linear Fonte: O próprio autor

\section{DIMENSIONAMENTO AO ESTADO LIMITE ÚLTIMO (ELU)}

Segundo a NBR 6118 (ABNT, 2014), o estado limite último está relacionado diretamente ao colapso de uma estrutura ou qualquer outra forma de ruína, que possa fazer com que haja a paralização da estrutura.

No entanto, podemos visualizar o pórtico deformado da estrutura ao ELU que é fornecido pelo software disponível na figura 61, para verificar esse estado, onde quando mais verde menor é o deslocamento da estrutura e quanto mais se aproxima do vermelho maior é o deslocamento do elemento estrutural. 


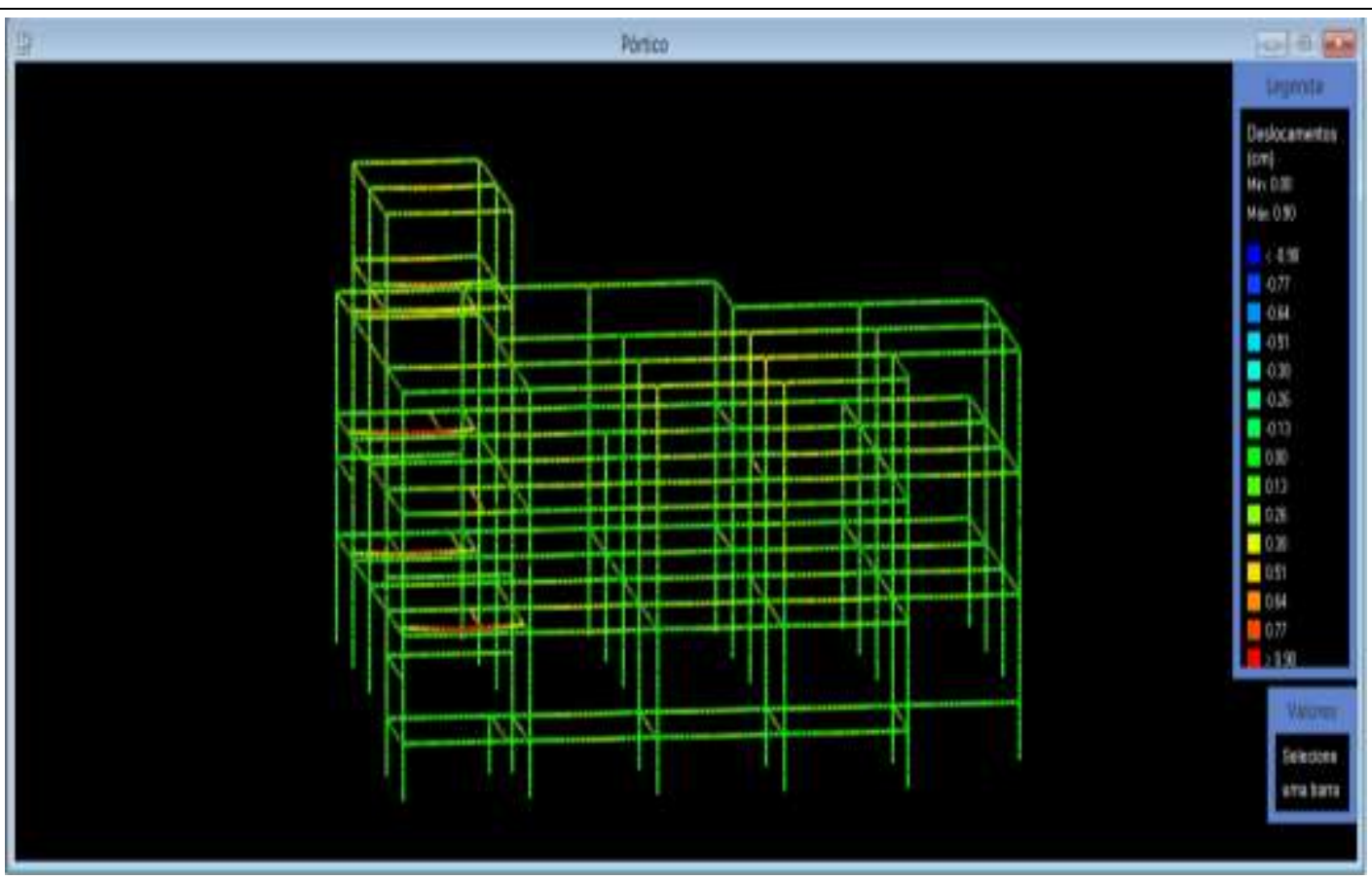

Figura 7 - Pórtico de deslocamento da estrutura ao (ELU)

Fonte: O próprio autor

\section{ESTABILIDADE ESTRUTURAL}

A estabilidade estrutural pode ser verificada por meio do coeficiente Gama$Z$, que tem seu limite máximo de 1,10 para a direção $X$ e para 1,10 para a direção $Y$, sendo assim, em nosso projeto obtivemos os seguintes resultados: 1,03 para a direção e 1,04 para direção $Y$, como gama-z ficou baixo de 1,10, teoricamente não precisaríamos levar em consideração os efeitos de segunda ordem pois se trata de uma estrutura de nós fixos, se fosse uma estrutura de nós moveis, gama z acima de 1,10, precisaríamos levar em consideração, traduzindo isso para o eberick, nas configurações de analise, poderíamos trabalhar com o P-Delta desligado. Para ficarmos a favor da segurança, mesmo com Gama-Z abaixo de 1,10, deixamos a configuração de P-Delta ligado, levando em considerações os efeitos de segunda ordem. Analise do Gama-Z na figura a seguir. 


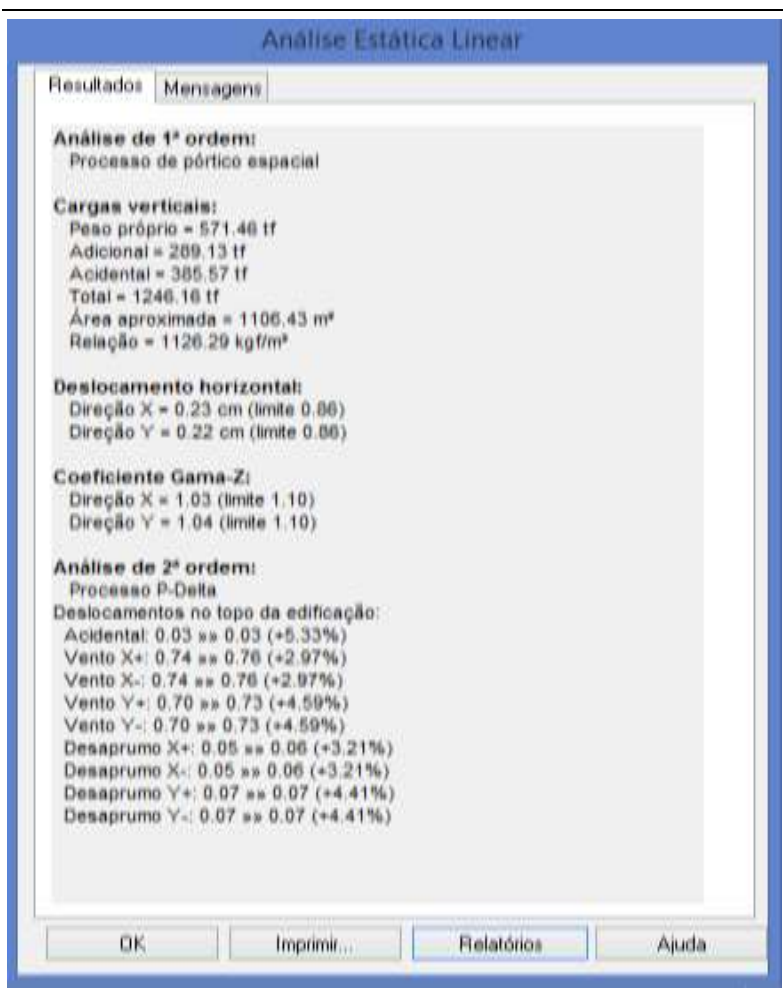

Figura 8 - Estabilidade estrutural

Fonte: O próprio autor

\section{DIMENSIONAMENTO AO ESTADO LIMITE DE SERVIÇO (ELS)}

O estado de limite de serviço nada mais é do que a relação entre o conforto dos usuários e sua segurança, além de contar com uma boa durabilidade, a estrutura tem que ter uma aparência boa e sua utilização tem que atender as necessidades a qual foi destinada.

Sendo assim, fica uma ressalva que nesta etapa, fazemos apenas as verificações quanto ao estado limite de serviço, como as flechas, por exemplo. Nesta etapa não costuma- se alterar muito os dimensionamentos, apenas se tivermos problemas de flechas e deformações excessivas.

\section{PROBLEMAS ENFRENTADOS AO DECORRER DO TRABALHO}

Durante a realização do deste trabalho de conclusão de curso, foram enfrentados diversos problemas, sendo todos diagnosticados após o processamento da estrutura, como pode ser observado na imagem 64. Diante desses problemas 
apresentados, foi buscado a melhor maneira de soluciona-los.

Como o software possui uma ferramenta de diagnóstico de erros, ele mesmo nos fornece o número do erro para facilitar a visualização do problema apresentado, da mesma maneira se ele te fornece os dados dos erros e uma solução alternativa para que esse erro seja sanado.

Já na escolha da melhor maneira de solucionar o erro fica a critério de quem está manuseando o software, pois é ele quem irá analisar se houve ou não alguma modificação quanto significativa no agrupamento os elementos, ou até mesmo na parte da estética da estrutura, não comprometendo a ideia inicial do projetista.

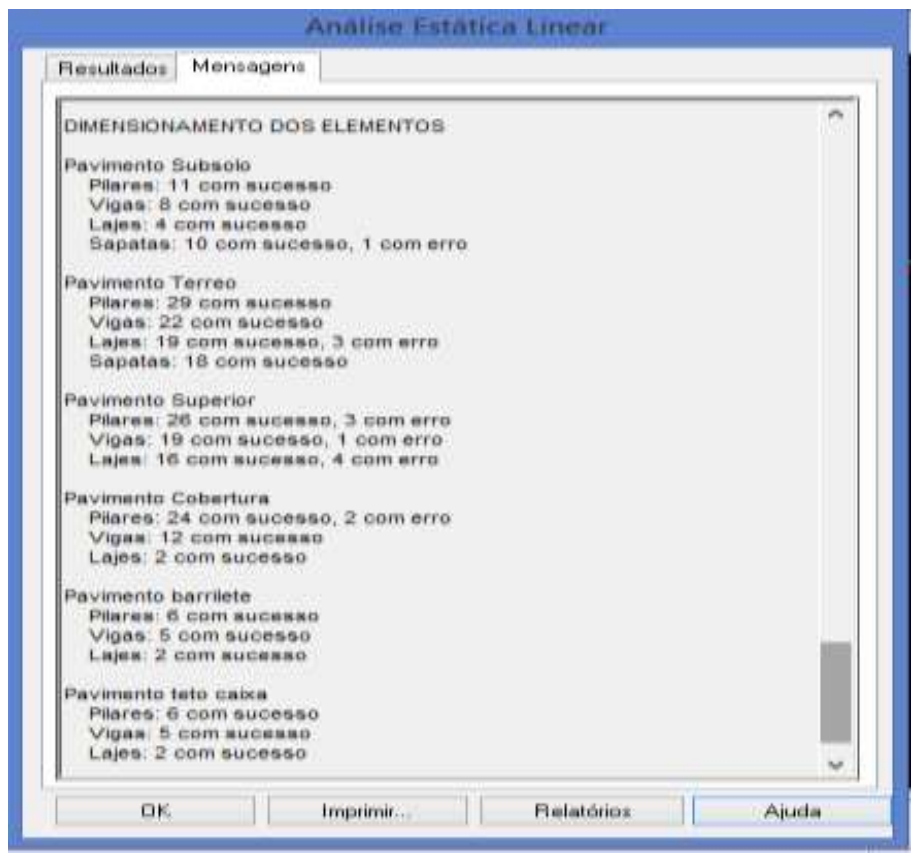

Figura 9 - Problemas apresentado após o processamento da estrutura Fonte: O próprio autor

\section{RESUMO DE MATERIAIS}

O resumo de materiais fornecidos pelo software são:

- Resumo do CA50 e CA60 de todas as bitolas, fornecidos em kg;

- Resumo do volume do concreto em fornecido em $\mathrm{m}^{3}$;

- Resumo da área de formas fornecido em $\mathrm{m}^{3}$;

- Consumo de aço fornecido kgf/m. 


\section{AltoQi}

\begin{tabular}{|c|r|r|r|r|r|r|c|}
\hline \multirow{2}{*}{ Aç0 } & \multirow{2}{*}{ Diâmetro } & \multicolumn{7}{|c|}{ Pes0 + $\mathbf{1 0}$ \% (kg) } \\
\cline { 3 - 8 } & & \multicolumn{1}{|c|}{ Vigas } & Pilares & \multicolumn{1}{c|}{ Lajes } & Escadas & Fundações & Total \\
\hline CA50 & 6.3 & 4.2 & & 984.9 & 85.9 & & 1075.1 \\
\hline CA50 & 8.0 & 89.6 & & 1945.1 & 148.6 & 15.4 & 2198.7 \\
\hline CA50 & 10.0 & 939.2 & & 3570.7 & 76.9 & 56.8 & 4643.6 \\
\hline CA50 & 12.5 & 1630.4 & 893.3 & 1510.6 & & 761.4 & 4795.7 \\
\hline CA50 & 16.0 & 2132.2 & 2152.6 & & & 464.5 & 4749.3 \\
\hline CA50 & 20.0 & 488.1 & & & & 2956.5 & 3444.6 \\
\hline CA60 & 5.0 & 762.3 & 533.3 & 67.1 & 0.4 & & 1363.1 \\
\hline
\end{tabular}

\begin{tabular}{|l|c|r|r|r|r|r|r|}
\hline \multicolumn{2}{|c|}{} & \multicolumn{1}{c|}{ Vigas } & Pilares & \multicolumn{1}{c|}{ Lajes } & Escadas & Fundações & \multicolumn{1}{c|}{ Total } \\
\hline \multirow{2}{*}{$\begin{array}{l}\text { Peso total } \\
+10 \%(\mathrm{~kg})\end{array}$} & CA50 & 5283.7 & 3046.0 & 8011.4 & 311.4 & 4254.5 & 20907.0 \\
\cline { 2 - 8 } & CA60 & 762.3 & 533.3 & 67.1 & 0.4 & & 1363.1 \\
\cline { 2 - 8 } & Total & 6046.0 & 3579.3 & 8078.5 & 311.8 & 4254.5 & 22270.1 \\
\hline Volume concreto $\left(\mathrm{m}^{2}\right)$ & C-30 & 64.0 & 30.1 & 127.2 & 8.0 & 56.0 & 285.3 \\
\hline Area de forma $\left(\mathrm{m}^{2}\right)$ & & 860.0 & 381.7 & 998.0 & 69.0 & 58.9 & 2367.6 \\
\hline \multicolumn{2}{|l|}{ Consumo de aço $\left(\mathrm{kgf}^{2} \mathrm{~m}^{2}\right)$} & 94.5 & 118.9 & 63.5 & 38.8 & 76.0 & 78.1 \\
\hline
\end{tabular}

Figura 10 - Resumo dos materiais

Fonte: O próprio autor

\section{CONCLUSÃO}

O desenvolvimento do presente trabalho, possibilitou verificar quais são os níveis de conhecimentos necessários para um melhor detalhamento e dimensionamento de uma cervejaria em concreto armado, utilizando assim, a ferramenta de cálculo Eberick, da empresa AltoQI. Entretanto, mesmo com a utilização de um software para o cálculo de toda a estrutura, percebeu- se que existe a abrangência de vários temas, que vai desde projeto arquitetônico até a escolha do melhor posicionamento dos elementos estruturais e dimensionamento mais adequado.

No entanto, este trabalho teve como objetivos específicos a realização de pesquisa bibliográfica em livros e artigos para aprofundar o conhecimento em concreto armado, buscando assim a melhor maneira de dimensionar a estrutura utilizando o software Eberick, concluindo foi feita a análise de todos resultados 
fornecidos pelo software.

Entretanto, mesmo com os cálculos sendo feitos automaticamente pelo software, é de suma importância que quem esteja manuseando o projeto seja um profissional qualificado, para que haja um perfeito equilíbrio entre o software e o conhecimento prático do profissional.

Portando, frisamos que este projeto ficou com o resultado dentro do esperado, ou seja, atendeu a todos os parâmetros exigidos pelas normas vigentes, obtendo assim, uma boa estabilidade da estrutura, bem como o perfeito agrupamento de todos os elementos estruturais.

\section{REFERÊNCIAS}

LEONHOART, F.; MÖNNING, E. Construções de concreto. Volume 1. Rio de Janeiro: Interciência, 2008.

ASSOCIAÇÃO BRASILEIRA DE NORMAS TÉCNICAS. NBR 6118: Projeto de estruturas de concreto - Procedimento. Rio de Janeiro, 2014. 